\title{
ROS/p53/miR-335-5p/Sp1 axis modulates the migration and epithelial to mesenchymal transition of JEG-3 cells
}

\author{
WEI LU ${ }^{1,2}$, YU-YAN MA ${ }^{1}$, QIAN-QIAN SHAO ${ }^{3}$, JIE LIANG $^{4}$, TONG-TONG QI ${ }^{5}$, \\ YI HUANG ${ }^{5}$ and QING-JIE WANG ${ }^{3}$
}

\begin{abstract}
${ }^{1}$ Department of Obstetrics and Gynecology; ${ }^{2}$ Key Laboratory of Gynecologic Oncology of Shandong Province;
${ }^{3}$ The Key Laboratory of Cardiovascular Remodeling and Function Research, Chinese Ministry of Education and

Chinese Ministry of Public Health, Institute of Basic Medical Sciences, Qilu Hospital of Shandong University,

Jinan, Shandong 250012; ${ }^{4}$ Central Sterile Supply Department, People's Hospital of Fangzi, Weifang, Shandong 261200;

${ }^{5}$ School of Pharmaceutical Science, Shandong University, Jinan, Shandong 250012, P.R. China
\end{abstract}

Received June 28, 2019; Accepted November 18, 2019

DOI: $10.3892 / \mathrm{mmr} .2019 .10901$

\begin{abstract}
Differential expression of microRNA (miR)-335-5p, a key tumor suppressor, has been detected in pre-eclampsia (PE) placentas. However, the role of miR-335-5p in the pathogenesis of $\mathrm{PE}$ and the factor modulating its aberrant expression remain unknown. The present study used JEG-3 cells in vitro to investigate these mechanisms. The role of miR-335-5p in proliferation, apoptosis and migration of JEG-3 cells was investigated using MTT, Annexin V-FITC/PI, Transwell migration and wound healing assays, respectively. miR-335-5p expression levels were analyzed using reverse transcription-quantitative PCR. The expression levels of E-cadherin, $\mathrm{N}$-cadherin, Snail, specificity protein 1 (Sp1) and p53 were assessed using western blot analysis. Cell viability analysis was performed using the Cell Counting Kit- 8 assay. The intracellular reactive oxygen species (ROS) levels were detected using a 2,7-dichlorodihydrofluorescein diacetate assay. The present results suggested that miR-335-5p did not affect the proliferation or apoptotic rate of JEG-3 cells. Overexpression of miR-335-5p significantly inhibited the migration of JEG-3 cells, decreased the expression levels of Sp1, N-cadherin and Snail, and increased E-cadherin expression. Sp1 silencing produced similar results in JEG-3 cells. $\mathrm{H}_{2} \mathrm{O}_{2}$ significantly increased the intracellular ROS levels and miR-335-5p expression, whereas $\mathrm{N}$-acetyl-cysteine pretreatment prior to $\mathrm{H}_{2} \mathrm{O}_{2}$ treatment reversed the increases in miR-335-5p expression. Knockdown of p53 significantly decreased the expression
\end{abstract}

Correspondence to: Dr Qing-Jie Wang, The Key Laboratory of Cardiovascular Remodeling and Function Research, Chinese Ministry of Education and Chinese Ministry of Public Health, Institute of Basic Medical Sciences, Qilu Hospital of Shandong University, 107 Wenhuaxi Road, Jinan, Shandong 250012, P.R. China E-mail: wqj_1025@163.com

Key words: microRNA-335-5p, reactive oxygen species, p53, migration, specificity protein 1 , epithelial to mesenchymal transition levels of miR-335-5p in JEG-3 cells and in $\mathrm{H}_{2} \mathrm{O}_{2}$-treated cells. The present results suggested that miR-335-5p expression levels in trophoblast cells could be increased by ROS in a p53-dependent manner, leading to the downregulation of Sp1 and subsequent inhibition of epithelial to mesenchymal transition and cell migration. The present results may provide novel evidence on the etiology of PE.

\section{Introduction}

Pre-eclampsia (PE) is a pregnancy-specific complication diagnosed by the onset of high blood pressure and proteinuria after 20 weeks of gestation, which affects 3-8\% of pregnancies globally $(1,2)$. Despite developments in the diagnosis and treatment of PE, the pathogenesis of PE requires further investigation. The abnormal placenta, characterized by impaired trophoblastic invasion and placental angiogenesis, can serve key roles in the occurrence and progression of $\mathrm{PE}(3,4)$. Investigating novel mechanisms for regulating placental function will improve the diagnosis and treatment of PE.

MicroRNAs (miRNAs/miRs) are endogenous small non-coding single-stranded RNAs, 22-25 nucleotides in length, which can modulate target gene expression via translational repression or degradation (5). The dysregulation of miRNAs contributes to various human diseases (6). Previous expression profiling studies have demonstrated dysregulated expression of miRNAs in the placenta of PE (7-9). In addition, miRNAs may be implicated in the pathogenesis of PE by regulating the function and development of the placenta $(10,11)$.

Among the differentially expressed miRNAs, miR-335-5p is significantly upregulated in PE-affected placentas $(9,12)$. Previous studies have demonstrated that miR-335-5p may have a negative correlation with neovascularization in human retinal microvascular endothelial cells and in patients with age-related macular degeneration $(13,14)$. In addition, miR-335-5p can serve as a key tumor suppressor to inhibit tumor invasion, metastasis and proliferation, and to induce apoptosis in different human cancer types (15). Dysregulated miR-335-5p may be associated with the pathogenesis of PE; however, the underlying mechanism regulating the aberrant 
expression of miR-335-5p in PE-affected placentas and the role of miR-335-5p in the pathogenesis of PE are not fully understood. The present in vitro study preliminarily investigated the role of miR-335-5p in JEG-3 cells.

\section{Materials and methods}

Cell culture. The JEG-3 choriocarcinoma line was purchased from Nanjing KeyGen Biotech Co., Ltd. Cells were cultured in minimum essential medium (MEM; Gibco; Thermo Fisher Scientific, Inc.) containing $10 \%$ heat-inactivated FBS (Biological Industries), $100 \mathrm{U} / \mathrm{ml}$ penicillin and $100 \mu \mathrm{g} / \mathrm{ml}$ streptomycin at $37^{\circ} \mathrm{C}$ in a humidified atmosphere with $5 \%$ $\mathrm{CO}_{2}$. Cells were passaged when confluence reached $\sim 90 \%$.

Cell transfection. JEG-3 cells were seeded in six-well plates at $5 \times 10^{5}$ cells/well, and transfected with $50 \mathrm{nM}$ miR-335-5p mimics, p53 small interfering (si)RNA, specificity protein 1 (Sp1) siRNA or the corresponding non-specific negative controls (NCs) using the riboFECT ${ }^{\mathrm{TM}} \mathrm{CP}$ Transfection kit (Guangzhou RiboBio Co., Ltd.), according to the manufacturer's protocol. miR-335-5p mimics, p53 siRNA, Sp1 siRNA and the corresponding NCs were designed and synthesized by Shanghai GenePharma Co., Ltd. miR-335-5p mimics, forward 5'-UCAAGAGCAAUAACGAAAAAUGU-3', reverse 5'-AUUUUUCGUUAUUGCUCUUGAUU-3'; p53 siRNA, forward 5'-GCAUGAACCGGAGGCCCAUTT-3', reverse 5'AUGGGCCUCCGGUUCAUGCTT-3'; Spl siRNA, forward 5'-UGAGAACAGCAACAACUCCTT-3', reverse 5'-GGA GUUGUUGCUGUUCUCATT-3'; and NCs, forward 5'-UUC UCCGAACGUGUCACGUTT-3' and reverse 5'-ACGUGA CACGUUCGGAGAATT-3'. The transfected cells were then collected for western blot analysis or other functional assays after 24, 48, 72 or $96 \mathrm{~h}$.

Cell proliferation. JEG-3 cells transfected with NCs or miR-335-5p mimics were seeded at a density of $5 \times 10^{3}$ cells/well in 96-well culture plates with $100 \mu \mathrm{l}$ complete medium under normal conditions. After culturing for 0, 24, 48, 72 and $96 \mathrm{~h}$, an MTT assay (Beyotime Institute of Biotechnology) was performed to measure cell proliferation. In total, $10 \mu \mathrm{l}$ MTT reagent was added to each well and the plate was incubated at $37^{\circ} \mathrm{C}$ for $4 \mathrm{~h}$. Subsequently, $100 \mu \mathrm{l}$ dimethyl sulfoxide was added to terminate the reaction. The optical density (OD) was measured at $490 \mathrm{~nm}$ using a microplate reader (Tecan Infinite M200; Tecan Group, Ltd.). The experiments were performed in triplicate.

Cell apoptosis. An Annexin V-FITC/PI apoptosis detection kit (cat. no. BB-4101-1, BestBio) was used to assess the cell apoptotic rate according to the manufacturer's instructions. After JEG-3 cells were transfected with NCs or miR-335-5p mimics for $48 \mathrm{~h}$, the cells were collected using trypsin without EDTA, washed twice with cold PBS and resuspended with $400 \mu \mathrm{l}$ binding buffer. The cells were incubated with $5 \mu \mathrm{l}$ Annexin V-FITC staining solution for $15 \mathrm{~min}$ at $4^{\circ} \mathrm{C}$ and $10 \mu \mathrm{l}$ PI staining solution for $5 \mathrm{~min}$ at $4^{\circ} \mathrm{C}$ in the dark. The apoptotic rate was detected using a flow cytometer (BD FACSCalibur flow cytometer; BD Biosciences). The flow cytometry data were analyzed with FlowJo software (v10.0.7r2; FlowJo LLC). The experiments were performed in triplicate.
Transwell migration assay. The effect of miR-335-5p or Sp1 on the migration of JEG-3 cells was evaluated using a Transwell migration assay in a 24-well Transwell plate containing polycarbonate filters with $8 \mu \mathrm{m}$ pores (Costar; Corning, Inc.). After transfection with miR-335-5p mimics, Sp1 siRNA or the corresponding NCs for $24 \mathrm{~h}, \mathrm{JEG}-3$ cells were trypsinized and adjusted to $1 \times 10^{6}$ cells $/ \mathrm{ml}$ in MEM. In total, $100 \mu \mathrm{l}$ resuspended cells was placed in the upper chamber and $600 \mu \mathrm{l}$ medium containing $10 \%$ FBS was added to the lower chamber. After incubation at $37^{\circ} \mathrm{C}$ for $24 \mathrm{~h}$ under normal conditions, the membranes were fixed using $100 \%$ methanol at room temperature for $30 \mathrm{~min}$ and stained with $0.1 \%$ crystal violet stain solution (cat. no. G1063, Beijing Solarbio Science $\&$ Technology Co., Ltd.) at room temperature for $20 \mathrm{~min}$. The numbers of migrated cells were calculated using a light microscope (magnification, x400; Olympus IX51; Olympus Corporation) in five random fields. The experiments were performed in triplicate.

Wound healing assay. The migratory ability of miR-335-5p was further investigated using a wound healing assay. JEG-3 cells were transfected with NCs or miR-335-5p mimics. After cells reached $90 \%$ confluence, a $10-\mu 1$ sterile pipette tip was used to create a wound in the monolayer. The cells were grown in FBS-free medium for another $24 \mathrm{~h}$ and evaluated using a light microscope (Olympus IX51; Olympus Corporation) in phase contrast condition, using magnification, $x 100$. The wound areas were measured using ImageJ software (version 1.46r; National Institutes of Health). The relative wound closure under each condition was calculated according to the following formula: Wound area measured at $0 \mathrm{~h}$ minus the wound area at $24 \mathrm{~h}$. The wound repair rate was obtained using the percentage of the relative wound closure within the wound area measured at $0 \mathrm{~h}$. The experiments were performed in triplicate.

Western blot analysis. Total proteins were extracted from JEG-3 cells transfected with miR-335-5p mimics, p53 siRNA, Sp1 siRNA or the corresponding NCs using RIPA lysis buffer (cat. no. P0013B; Beyotime Institute of Biotechnology), according to the manufacturer's instructions. Protein concentration was measured using an Enhanced Bicinchoninic Acid Protein assay kit (Beyotime Institute of Biotechnology). A total of $10 \mu \mathrm{g}$ each sample was separated by SDS-PAGE on $12 \%$ gels according to the assigned groups and electrophoretically transferred to PVDF membranes (EMD Millipore). After the membranes were blocked with TBS-0.1\% Tween 20 (TBST) containing $5 \%$ non-fat dry milk at room temperature for $1 \mathrm{~h}$, membranes were incubated with primary antibodies against Sp1 (1:1,000; cat. no. ab124804; Abcam), p53 (1:1,000; cat. no. 10442-1-AP; Wuhan Sanying Biotechnology), E-cadherin (1:1,000; cat. no. 20874-1-AP; Wuhan Sanying Biotechnology), N-cadherin (1:2,000; cat. no. ab76011; Abcam), Snail (1:1,000; cat. no. 26183-1-AP; Wuhan Sanying Biotechnology) and GAPDH (1:2,000; cat. no. 10494-1-AP; Wuhan Sanying Biotechnology) at $4^{\circ} \mathrm{C}$ overnight. Subsequently, the membranes were washed three times with TBST for $10 \mathrm{~min}$ and exposed to horseradish peroxidase-conjugated affiniPure goat anti-rabbit IgG $(\mathrm{H}+\mathrm{L}$; 1:5,000; cat. no. SA00001-2; Wuhan Sanying Biotechnology) at room temperature for $1 \mathrm{~h}$. Detections were performed 
using an enhanced chemiluminescence kit (Wuhan Sanying Biotechnology). The bands were semi-quantified with densitometry using ImageJ software. The target protein levels were presented as fold change normalized to GAPDH in each sample.

$\mathrm{H}_{2} \mathrm{O}_{2}$ treatment andreactive oxygen species (ROS) assay.JEG-3 cells were plated in 6 -well plates at $8 \times 10^{5}$ cells $/$ well and were treated with $0.1 \mathrm{mM} \mathrm{H}_{2} \mathrm{O}_{2}$ at $37^{\circ} \mathrm{C}$ for $24 \mathrm{~h}$. N-acetyl-cysteine (NAC), a specific scavenger of ROS, was purchased from Sigma-Aldrich; Merck KGaA. To investigate the effect of ROS on the expression of miR-335-5p, JEG-3 cells were treated with $10 \mathrm{mM} \mathrm{NAC}$ at $37^{\circ} \mathrm{C}$ for $1 \mathrm{~h}$ prior to $\mathrm{H}_{2} \mathrm{O}_{2}$ treatment. The intracellular ROS levels induced by $\mathrm{H}_{2} \mathrm{O}_{2}$ with or without NAC were detected with a ROS assay kit (cat. no. BB-4705; BestBio) according to the manufacturer's instructions. After the cells were treated with $\mathrm{H}_{2} \mathrm{O}_{2}$ with or without NAC in 6-well plates as aforementioned, the supernatants were removed and cells were washed three times with PBS. Cells were incubated in fresh medium with DCFH-DA at $37^{\circ} \mathrm{C}$ for $20 \mathrm{~min}$. Cells were collected, washed two times with PBS and analyzed with a flow cytometer (BD FACSCalibur flow cytometer; BD Biosciences) with the excitation wavelength at $488 \mathrm{~nm}$ and the emission wavelength at $525 \mathrm{~nm}$. The flow cytometry data were analyzed with FlowJo software. The experiments were performed in triplicate.

Cell viability assay. Cell viability was evaluated using the CCK-8 assay (Bestbio), according to the manufacturer's protocols. JEG-3 cells were cultured in a 96-well plate at $5 \times 10^{3}$ cells/well with MEM containing $10 \%$ FBS. After incubation with $0.1 \mathrm{mM} \mathrm{H}_{2} \mathrm{O}_{2}$ at $37^{\circ} \mathrm{C}$ for $24 \mathrm{~h}, 10 \mu \mathrm{l} \mathrm{CCK}-8$ solution was added to each well and incubated at $37^{\circ} \mathrm{C}$ for $3 \mathrm{~h}$. The OD values were detected at $450 \mathrm{~nm}$ using a microplate reader (Tecan Infinite M200; Tecan Group, Ltd.). Relative cell viability was calculated using the following formula: $\mathrm{OD}\left(\mathrm{H}_{2} \mathrm{O}_{2}\right) / \mathrm{OD}$ (control) $\times 100 \%$. The experiments were performed in triplicate.

Reverse transcription-quantitative PCR (RT-qPCR). Total RNA was extracted using the miRNeasy mini kit (cat. no. 217004; Qiagen, Inc.), according to the manufacturer's instructions. Reverse transcription and RT-qPCR for the expression of miR-335-5p was performed using a Hairpin- $-i^{\mathrm{TM}}$ microRNA and U6 snRNA Normalization RT-PCR Quantitation kit (Shanghai GenePharma Co., Ltd.) on an ABI 7700 PCR Instrument (Applied Biosciences; Thermo Fisher Scientific, Inc.). The conditions used for reverse transcription reaction according to the manufacturer's protocols were: $25^{\circ} \mathrm{C}$ for $30 \mathrm{~min}, 42^{\circ} \mathrm{C}$ for $30 \mathrm{~min}, 85^{\circ} \mathrm{C}$ for $5 \mathrm{~min}$ and hold at $4^{\circ} \mathrm{C}$. The following primers were used: hsa-miR-335-5p, forward 5'-CGT CCTCGTCAAGAGCAATAAC-3', reverse 5'-TATGCTTGT TCTCGTCTCTGTGTC-3'; and hU6, forward 5'-CAGCAC ATATACTAAAATTGGAACG-3' and reverse 5'-ACGAAT TTGCGTGTCATCC-3'. The following thermocycling conditions were used for qPCR according to the manufacturer's protocols: Initial denaturation at $95^{\circ} \mathrm{C}$ for $3 \mathrm{~min}$; followed by 40 cycles at $95^{\circ} \mathrm{C}$ for $12 \mathrm{sec}$ and $60^{\circ} \mathrm{C}$ for $40 \mathrm{sec}$. U6 snRNA was used as an internal reference. The expression levels of miR-335-5p were quantified using the $2^{-\Delta \Delta \mathrm{Cq}}$ method (16) according to the manufacturer's instructions.
Statistical analysis. Statistical analysis was performed using SPSS Statistics 21.0 software (IBM Corp.). Data are presented as the mean \pm SD from $\geq 3$ independent experiments. An unpaired Student's t-test was used to compare two groups, and one-way ANOVA followed by Bonferroni's multiple comparison test was used to compare $\geq 3$ groups for statistical analyses. $\mathrm{P}<0.05$ was considered to indicate a statistically significant difference.

\section{Results}

miR-335-5p does not affect proliferation or apoptosis of $J E G-3$ cells. To analyze the effects of miR-335-5p on JEG-3 cells, miR-335-5p mimics or corresponding non-specific NCs were transfected into JEG-3 cells. Transfection efficiency of miR-335-5p and NCs was confirmed by RT-qPCR (Fig. 1A). MTT assay and Annexin V-FITC/PI assay results suggested that ectopic overexpression of miR-335-5p did not affect proliferation (Fig. 1B) or apoptosis of JEG-3 cells (Fig. 1C and D).

miR-335-5p significantly suppresses the migration of JEG-3 cells. The role of miR-335-5p in the migration of JEG-3 cells was investigated using a Transwell cell migration assay and wound healing assay. Compared with the NCs group, the number of migrated cells was significantly lower in miR-335-5p-transfected-JEG-3 cells ( $43 \pm 9$ vs. $25 \pm 6$; $\mathrm{P}<0.001$; Fig. 2A and B). The wound healing assay results also showed similar effects (wound repair of the NCs group, 25.84 $\pm 4.10 \%$; wound repair of the miR-335-5p mimics group, $11.90 \pm 1.48 \%$; $\mathrm{P}<0.01$; Fig. $2 \mathrm{C}$ and D). Epithelial to mesenchymal transition (EMT) is critical for normal pregnancy and its dysregulation may be associated with several pregnancy disorders $(17,18)$. Since EMT is implicated in cell migration, the present study investigated whether miR-335-5p inhibited the migration of JEG-3 cells via the EMT markers E-cadherin, N-cadherin and Snail. The expression levels of $\mathrm{N}$-cadherin $(\mathrm{P}<0.05)$ and Snail $(\mathrm{P}<0.01)$ were significantly decreased in JEG-3 cells transfected with miR-335-5p mimics for $48 \mathrm{~h}$ compared with those transfected with NCs (Fig. 2E and F). Conversely, overexpression of miR-335-5p for $24 \mathrm{~h}(\mathrm{P}<0.05)$ or $48 \mathrm{~h}(\mathrm{P}<0.001)$ significantly increased E-cadherin expression in JEG-3 cells. The expression levels of $\mathrm{N}$-cadherin and Snail exhibited no significant difference between JEG-3 cells transfected with miR-335-5p mimics for 24 and $48 \mathrm{~h}$, whereas E-cadherin expression was significantly increased in the miR-335-5p mimics $48 \mathrm{~h}$ group compared with the $24 \mathrm{~h}$ group $(\mathrm{P}<0.001)$.

Spl participates in the inhibitory role of $\mathrm{miR}-335-5 \mathrm{p}$ on cell migration. Sp1 serves important roles in the progression of EMT $(19,20)$. A previous study revealed that $\mathrm{Sp1}$ was the target of miR-335-5p in gastric cancer (21). The present study investigated whether miR-335-5p inhibited the migration of JEG-3 cells via Sp1. The present western blotting results suggested that overexpression of miR-335-5p for $24 \mathrm{~h}(\mathrm{P}<0.01)$ or $48 \mathrm{~h}(\mathrm{P}<0.05)$ significantly decreased Sp1 expression in JEG-3 cells (Fig. 3A and B). Compared with the NCs-transfected cells, JEG-3 cells transfected with a Sp1-specific siRNA for 24 and $48 \mathrm{~h}$ exhibited significantly decreased expression levels of Sp1, N-cadherin and Snail, whereas the expression levels of E-cadherin were 


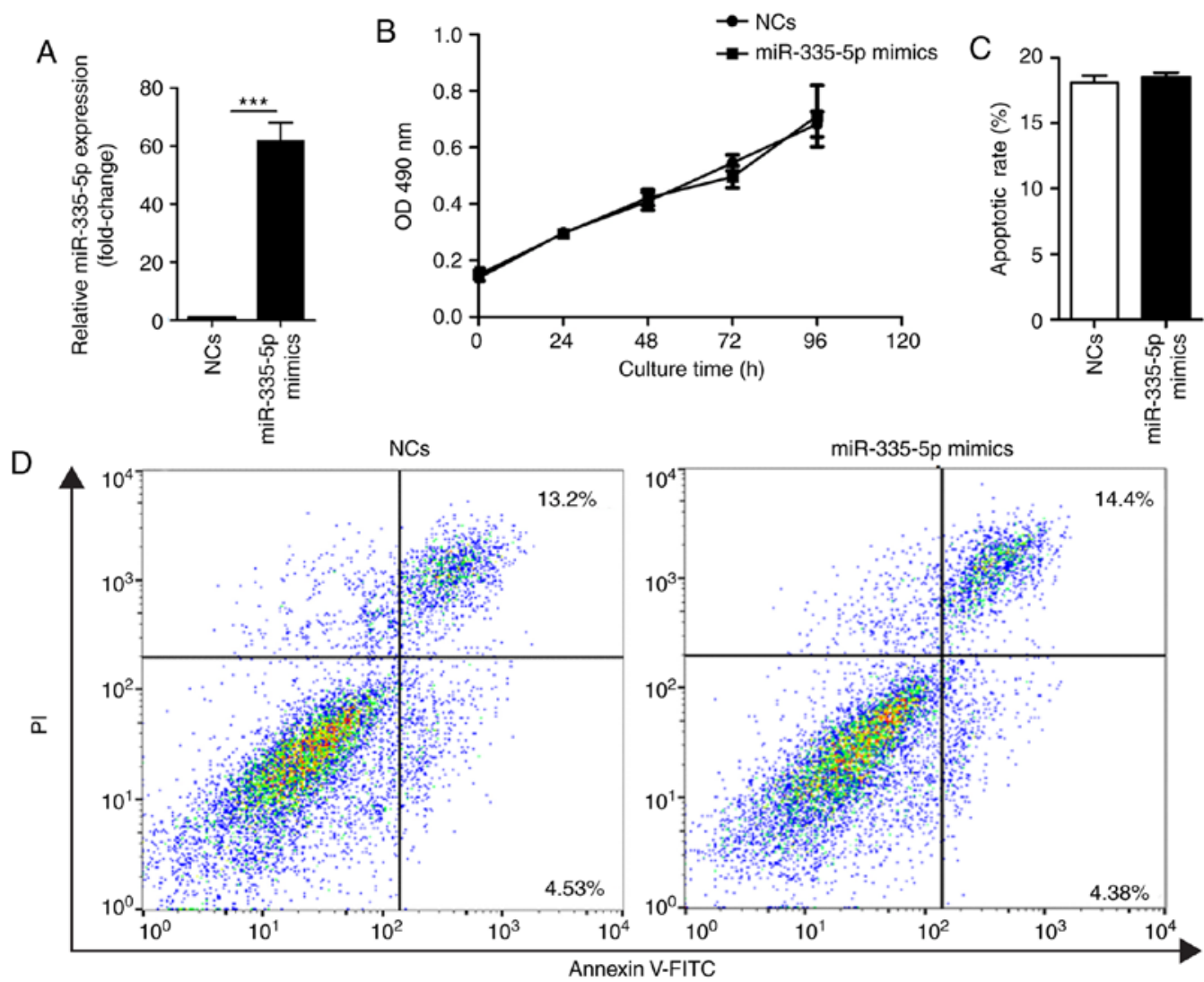

Figure 1. Ectopic overexpression of miR-335-5p does not affect the proliferation or apoptosis of JEG-3 cells. (A) Reverse transcription-quantitative PCR results of the relative miR-335-5p expression in JEG-3 cells transfected with NCs or miR-335-5p mimics for 48 h. U6 small nuclear RNA was used as an internal reference. Compared with NCs, miR-335-5p mimics significantly increased miR-335-5p expression by $61.83 \pm 6.11$-fold. $n=3$. (B) Ectopic overexpression of miR-335-5p did not affect the proliferation of JEG-3 cells. (C) Statistical analysis showed that miR-335-5p overexpression did not affect the apoptotic rate of JEG-3 cells. $n=3$. (D) Representative images of apoptotic rates using Annexin V-FITC/PI staining and flow cytometry. ${ }^{* * *} \mathrm{P}<0.001$. miR-335-5p, microRNA-335-5p; NCs, negative controls; OD, optical density.

significantly increased $(\mathrm{P}<0.05)$. There was no difference in the expression levels of E-cadherin, N-cadherin and Snail between JEG-3 cells transfected with Sp1 siRNA for 24 and $48 \mathrm{~h}$ (Fig. 3C and D). In addition, silencing Sp1 in JEG-3 cells significantly decreased the migratory ability of cells (NCs, $68 \pm 22$ vs. Sp1 siRNA, 41 \pm 9 ; P<0.01; Fig. 3E and F). The present results suggested that $\mathrm{Sp} 1$ may mediate the inhibitory role of miR-335-5p in cell migration by regulating the expression levels of EMT markers.

Oxidative stress induced by $\mathrm{H}_{2} \mathrm{O}_{2}$ increases miR-335-5p expression level. Previous studies have shown that oxidative stress can modulate miRNA expression in cancer via ROS $(22,23)$. The present study investigated ROS generation and miR-335-5p expression in JEG-3 cells following $\mathrm{H}_{2} \mathrm{O}_{2}$ exposure. The present results suggested that short-term exposure to $0.1 \mathrm{mM} \mathrm{H}_{2} \mathrm{O}_{2}$ for $24 \mathrm{~h}$ did not affect the viability of JEG-3 cells (Fig. 4A). Compared with control cells, the intracellular ROS levels detected using the DCFH-DA assay and miR-335-5p expression levels identified by RT-qPCR were significantly higher in JEG-3 cells treated with $0.1 \mathrm{mM}$ $\mathrm{H}_{2} \mathrm{O}_{2}$ for $24 \mathrm{~h}(\mathrm{P}<0.001)$. Cells pretreated with $10 \mathrm{mM} \mathrm{NAC}$ for $1 \mathrm{~h}$ prior to $\mathrm{H}_{2} \mathrm{O}_{2}$ treatment had significant decreases in intracellular ROS levels and miR-335-5p expression compared with cells exposed to $\mathrm{H}_{2} \mathrm{O}_{2}$ only $(\mathrm{P}<0.001$; Fig. 4B-D). p53 mediates the ROS-induced increase of miR-335-5p. miRNA expression can be regulated by ROS via several important transcription factors, including p53 $(22,24)$. The present study investigated whether 553 mediated the ROS-induced increase in expression levels of miR-335-5p in JEG-3 cells. Compared with in NCs-transfected cells, a p53-specific siRNA significantly decreased the expression levels of p53 after transfection for 24 and $48 \mathrm{~h}(\mathrm{P}<0.001$; Fig. 5A and B). Silencing p53 in JEG-3 cells significantly reduced miR-335-5p expression and significantly reversed the increased expression of miR-335-5p induced by $0.1 \mathrm{mM} \mathrm{H} \mathrm{H}_{2} \mathrm{O}_{2}$ exposure for $24 \mathrm{~h}$ $(\mathrm{P}<0.001$; Fig. 5C).

\section{Discussion}

Several miRNAs are involved in the regulation of normal pregnancy and pregnancy complications, such as PE $(10,11)$. Identifying the mechanism underlying dysregulated miRNA expression and the roles of miRNA will help understand the etiology of PE $(10,11)$.

miR-335-5p is downregulated in various types of human cancer, and is associated with tumorigenesis and cancer progression (15). Previous studies have reported that miR-335-5p is upregulated in PE placentas $(9,12)$. The present study investigated the role of miR-335-5p in the proliferation of JEG-3 cells. The present results suggested that miR-335-5p 

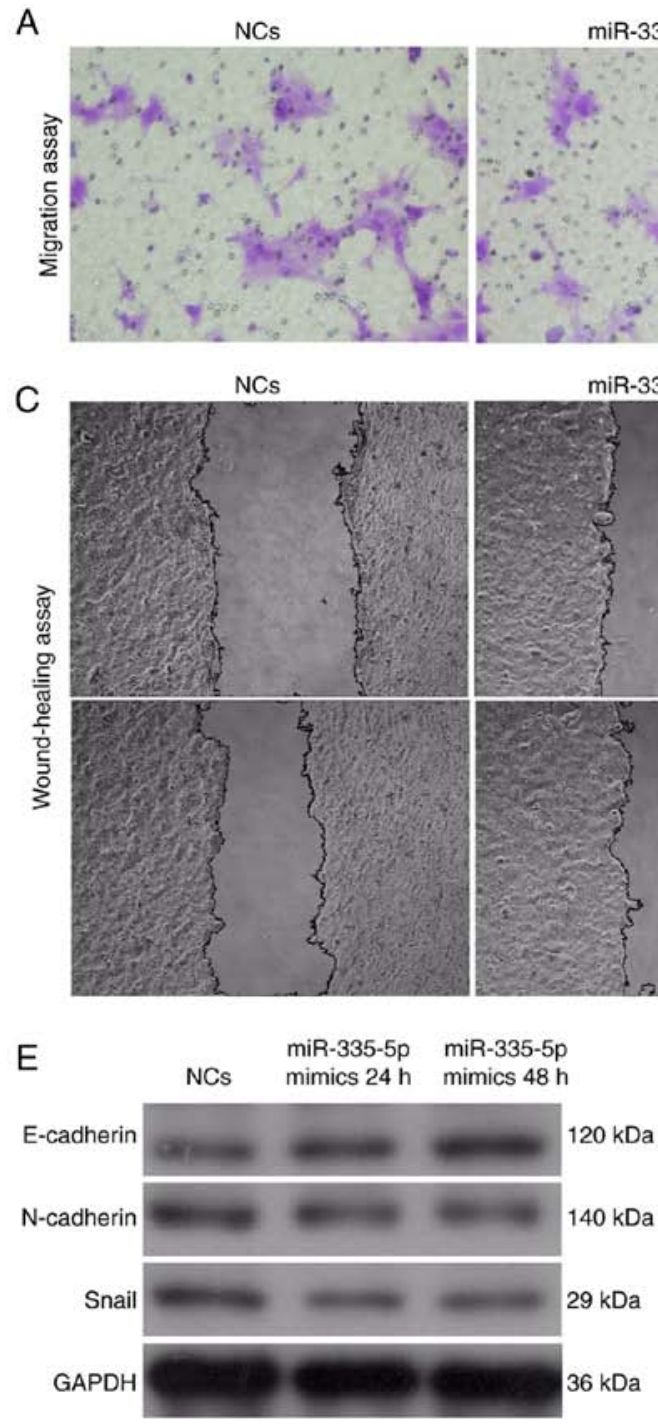

miR-335-5p mimics

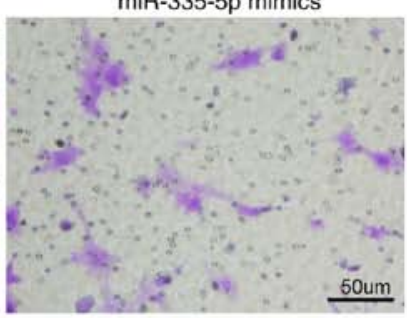

miR-335-5p mimics

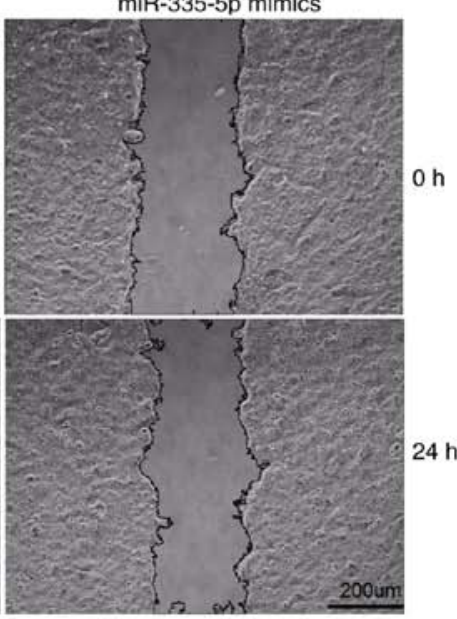

B

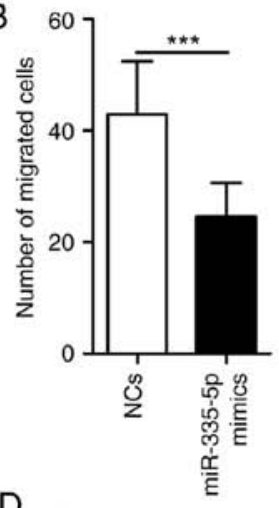

D

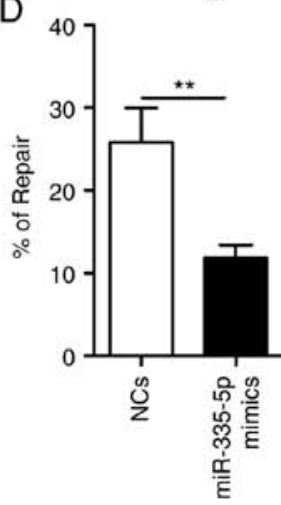

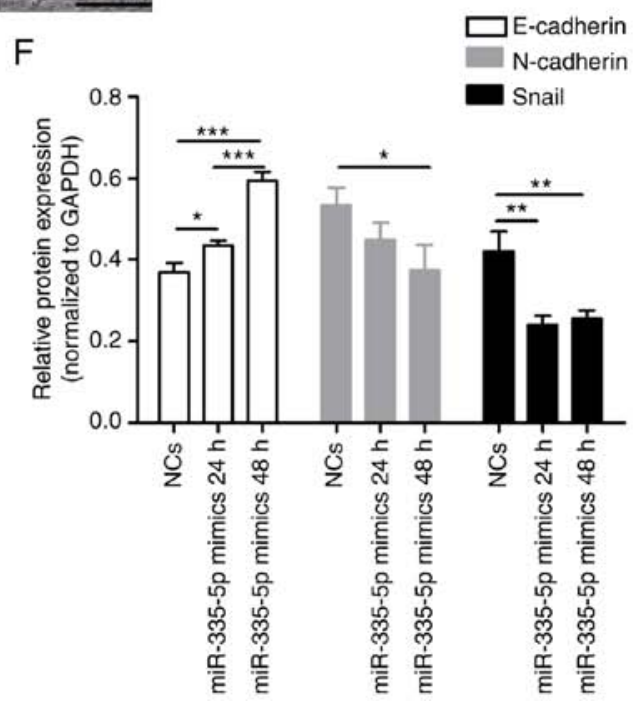

Figure 2. miR-335-5p significantly suppresses the migration of JEG-3 cells by modulating epithelial to mesenchymal transition markers. (A) Representative images of migrated JEG-3 cells transfected with NCs or miR-335-5p mimics in the Transwell migration assay. Scale bar, $50 \mu \mathrm{m}$. (B) Statistical analysis of the effect of NCs and miR-335-5p mimics on the migration of JEG-3 cells. NCs, $43 \pm 9$ vs. miR-335-5p mimics, $25 \pm 6$. $n=3$. The number of migrated cells was counted using a microscope in five independent symmetrical visual fields in each independent experiment. (C) Representative images of the wound healing assay in JEG-3 cells transfected with NCs or miR-335-5p mimics. Scale bar, $200 \mu \mathrm{m}$. (D) Semi-quantification of wound repair. NCs, $25.84 \pm 4.10 \%$ vs. miR-335-5p mimics, $11.90 \pm 1.48 \%$. n=3. (E) Western blot analysis of the protein expression levels of E-cadherin, N-cadherin and Snail in JEG-3 cells transfected with NCs and miR-335-5p mimics. GAPDH was used as the internal control. (F) Statistical analysis showing the effect of NCs and miR-335-5p mimics on the protein expression levels of E-cadherin, $\mathrm{N}$-cadherin and Snail in JEG-3 cells. ${ }^{*} \mathrm{P}<0.05,{ }^{* *} \mathrm{P}<0.01,{ }^{* * *} \mathrm{P}<0.001$. miR-335-5p, microRNA-335-5p; NCs, negative controls.

had no obvious effect on the proliferation or apoptosis of JEG-3 cells. Similarly, in previous studies, miR-335-5p did not regulate proliferation of gastric cancer cells and gastrin-releasing peptide receptor-silenced neuroblastoma cells $(21,25)$. However, in another previous study, miR-335-5p inhibited the proliferation of granulosa cells via SGK3 in polycystic ovary syndrome (26). The differences in cell source organizations may lead to the inconsistent evidence of the role of miR-335-5p.
miR-335-5p serves crucial roles in the migration and invasion of various types of human cancer by regulating different target genes (15). miR-335-5p can directly or indirectly modulate the EMT process, which serves as the driver of migration and invasion in cancer $(27,28)$. During placental implantation, the transformation of villous cytotrophoblasts to extravillous trophoblasts is similar to the process of EMT $(18,29)$. The dysregulation of this progress is associated with pregnancy complications $(17,18)$. Previous studies have 


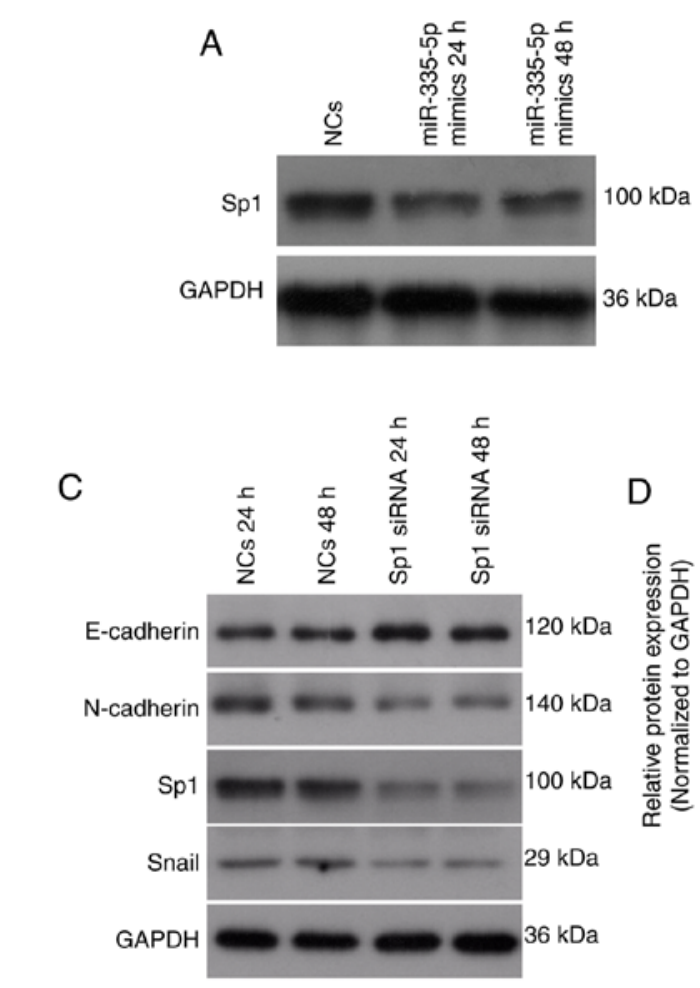

$\mathrm{B}$
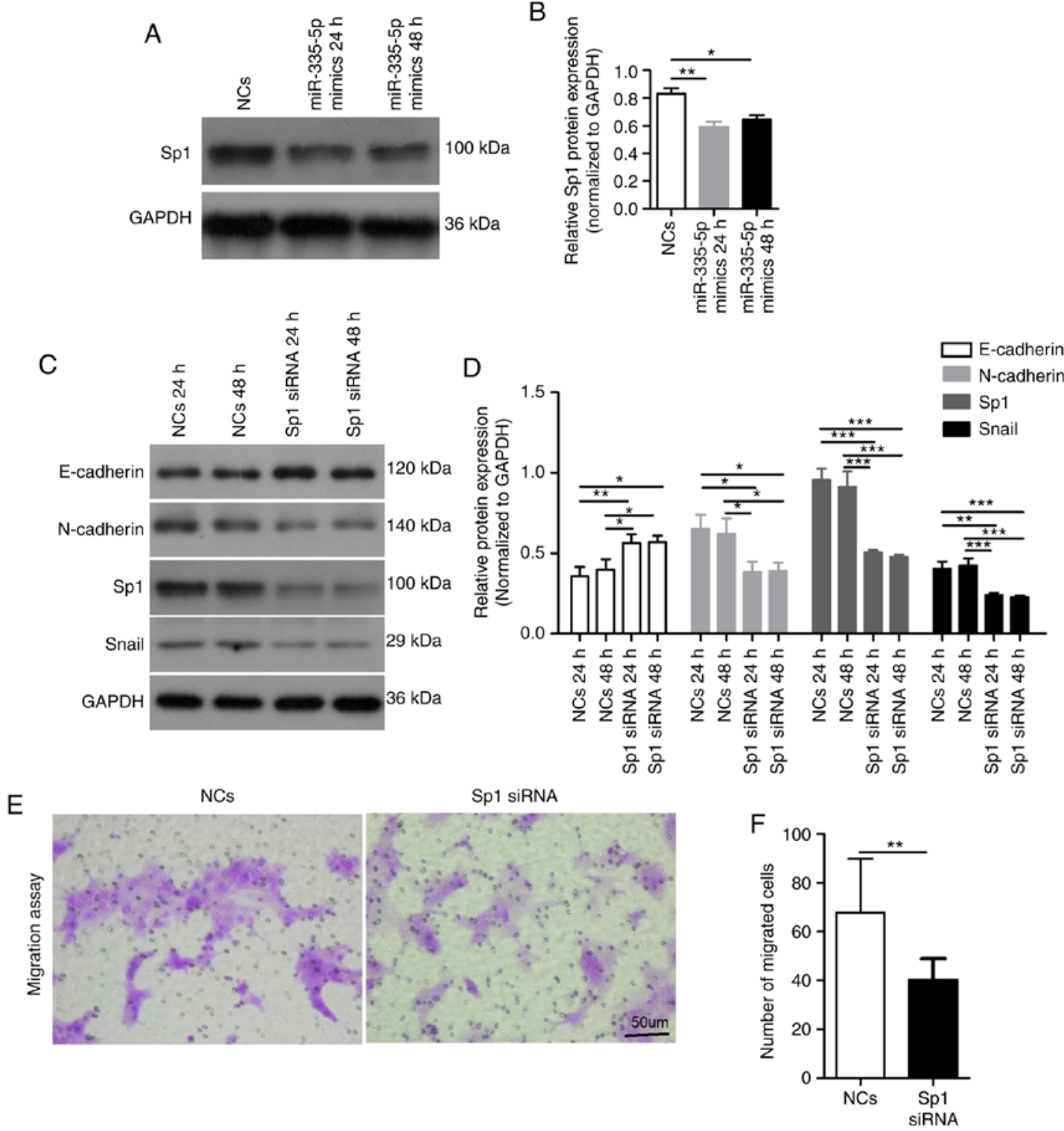

Figure 3. Sp1 participates in the inhibitory role of miR-335-5p in cell migration. (A) Western blot analysis of Sp1 expression in JEG-3 cells transfected with NCs and miR-335-5p mimics. GAPDH was used as the internal control. (B) Statistical analysis showing the effect of NCs or miR-335-5p mimics on Sp1 expression in JEG-3 cells. $n=3$. (C) Western blot analysis of the protein expression levels of E-cadherin, $\mathrm{N}$-cadherin, Sp1 and Snail in JEG-3 cells transfected with NCs or Sp1-specific siRNA. (D) Statistical analysis showing the effect of NCs and Sp1-specific siRNA on the protein expression levels of E-cadherin, N-cadherin, Sp1 and Snail in JEG-3 cells. n=3. (E) Representative images of migrated JEG-3 cells transfected with NCs or Sp1-specific siRNA in the Transwell migration assay. Scale bar, $50 \mu \mathrm{m}$. (F) Statistical analysis showing the effect of NCs and Sp1-specific siRNA on the migration of JEG-3 cells; NCs, $68 \pm 22$ vs. Sp1 siRNA, 41 \pm 9 . The number of migrated cells was counted using a microscope in five independent symmetrical visual fields in each independent experiment. $\mathrm{P}<0.05$, ${ }^{* *} \mathrm{P}<0.01,{ }^{* * *} \mathrm{P}<0.001$. miR-335-5p, microRNA-335-5p; NCs, negative controls; siRNA, small interfering RNA; Sp1, specificity protein 1.

reported that E-cadherin expression is markedly increased in placenta tissues from patients with PE compared with controls, whereas the expression levels of $\mathrm{N}$-cadherin and Snail are decreased (30-32). On the basis of these previous studies, the present study investigated the effects of miR-335-5p on JEG-3 cell migration and key EMT markers. The present results suggested that overexpression of miR-335-5p significantly inhibited JEG-3 cell migration, suppressed the expression levels of $\mathrm{N}$-cadherin and Snail, and increased E-cadherin expression. The present results were consistent with a previous study on the regulation of miR-335-5p on EMT in colorectal cancer cells (27). The present results suggested that miR-335-5p may affect the migration of trophoblast cells by regulating E-cadherin, N-cadherin and Snail.
Sp1 participates in the process of EMT by regulating the expression of EMT markers $(19,20,33)$. A previous study identified that in gastric cancer, Sp1 was a target of miR-335-5p (21). Another previous study revealed that $\mathrm{Sp} 1$ expression was significantly lower in PE placenta tissues compared with normal controls (34), which was contrary to the expression tendency of miR-335-5p in PE placental tissues $(9,12)$. The present study investigated the role of $\mathrm{Spl}$ in the relationship between miR-335-5p and EMT in JEG-3 cells. The present results suggested that miR-335-5p negatively regulated Sp1 expression levels in JEG-3 cells, and Sp1 knockdown significantly inhibited the EMT process and migration of JEG-3 cells. The present results suggested that $\mathrm{Spl}$ may participate in the inhibitory role of miR-335-5p in cell migration via regulation of the EMT process. 

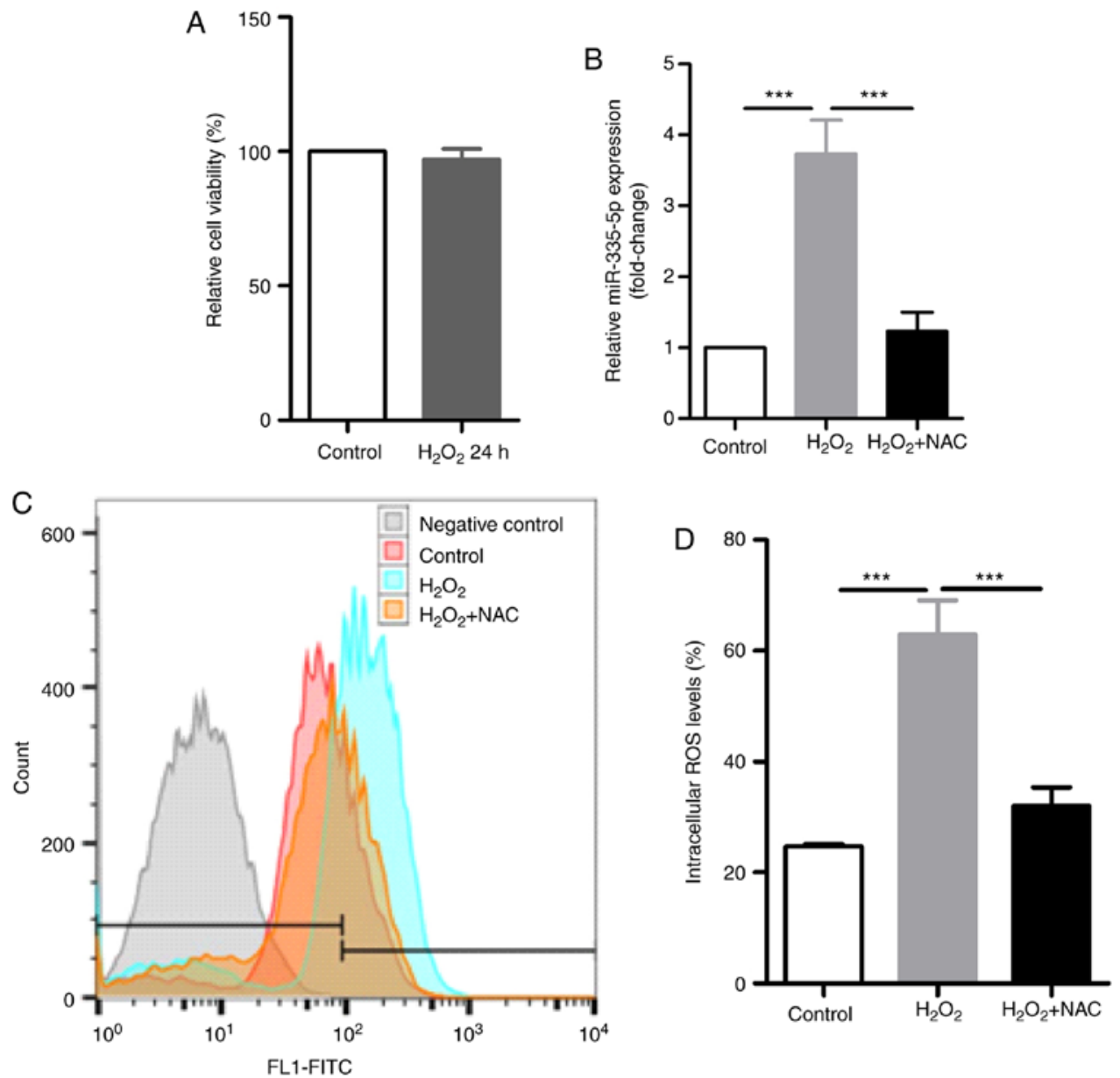

Figure 4. Oxidative stress induced by $\mathrm{H}_{2} \mathrm{O}_{2}$ increases miR-335-5p expression. (A) JEG-3 cells were exposed to $0.1 \mathrm{mM} \mathrm{H}_{2} \mathrm{O}_{2}$ for $24 \mathrm{~h}$ and cell viability was investigated using a Cell Counting Kit- 8 assay. $\mathrm{n}=3$. There was no significant difference in cell viability between the control group and the $\mathrm{H}_{2} \mathrm{O}_{2}$-treated group. (B) Compared with control cells, miR-335-5p expression was significantly increased in JEG-3 cells after $0.1 \mathrm{mM} \mathrm{H}_{2} \mathrm{O}_{2}$ exposure for $24 \mathrm{~h}$ by $3.73 \pm 0.48$-fold Compared with JEG-3 cells exposed to $0.1 \mathrm{mM} \mathrm{H}_{2} \mathrm{O}_{2}$ alone, miR-335-5p expression was significantly reversed by pretreating JEG-3 cells with $10 \mathrm{mM}$ NAC for $1 \mathrm{~h}$ prior to $\mathrm{H}_{2} \mathrm{O}_{2}$ exposure (3.73 \pm 0.48 -fold increase in $\mathrm{H}_{2} \mathrm{O}_{2}$ group vs. Control; $1.23 \pm 0.27$-fold increase in $\mathrm{NAC}+\mathrm{H}_{2} \mathrm{O}_{2}$ group vs. Control). $\mathrm{n}=3$. (C) Representative flow cytometry image of intracellular ROS levels using a 2,7-dichlorodihydrofluorescein diacetate assay. (D) Statistical analysis of the intracellular ROS levels in control cells, in JEG-3 cells after $0.1 \mathrm{mM} \mathrm{H}_{2} \mathrm{O}_{2}$ exposure for $24 \mathrm{~h}$ and in JEG-3 cells pretreated with $10 \mathrm{mM} \mathrm{NAC}$ for $1 \mathrm{~h}$ prior to $\mathrm{H}_{2} \mathrm{O}_{2}$ exposure. $\mathrm{n}=3 . \mathrm{H}_{2} \mathrm{O}_{2}$ exposure significantly increased the intracellular ROS levels in JEG-3 cells, whereas 10 mM NAC pretreatment significantly reversed the increase of ROS. ${ }^{* * *} \mathrm{P}<0.001$. miR-335-5p, microRNA-335-5p; NAC, N-acetyl-cysteine; NCs, negative controls; ROS, reactive oxygen species.
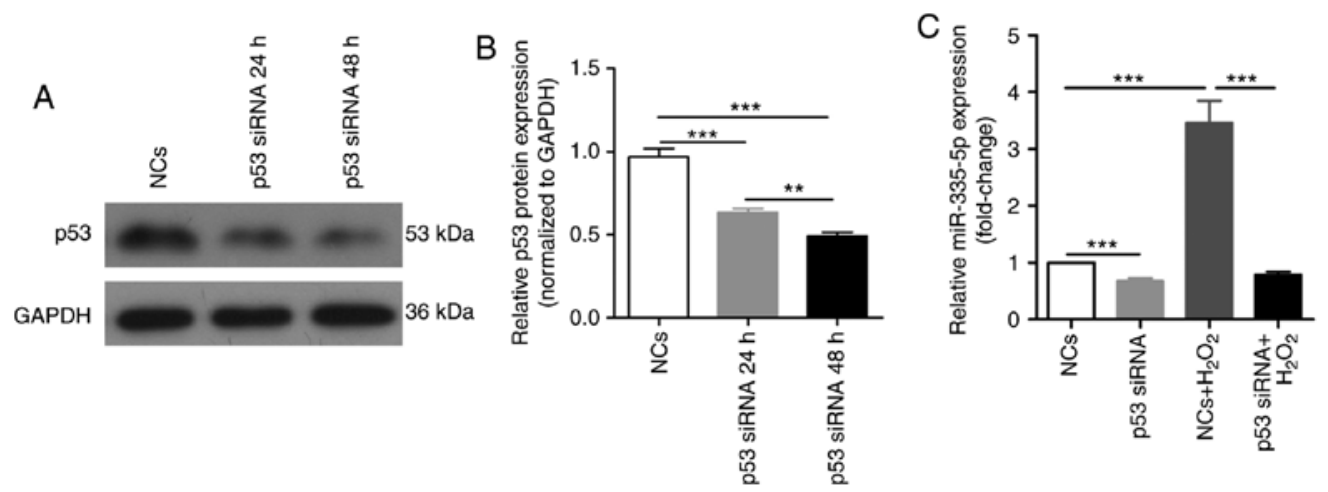

Figure 5. p53 mediates the ROS-induced increase in miR-335-5p expression. (A) Western blot analysis of p53 protein expression levels in JEG-3 cells transfected with NCs and p53-specific siRNA. GAPDH was used as the internal control. (B) Statistical analysis of the effect of NCs and p53-specific siRNA on p53 protein expression in JEG-3 cells. $n=3$. (C) JEG-3 cells were transfected with NCs or p53-specific siRNA for $24 \mathrm{~h}$, and further treated with $0.1 \mathrm{mM} \mathrm{H}_{2} \mathrm{O}_{2}$ for $24 \mathrm{~h}$. The expression levels of miR-335-5p in the four groups were analyzed using reverse transcription-quantitative PCR. ${ }^{* *} \mathrm{P}<0.01,{ }^{* * * *} \mathrm{P}<0.001$. miR-335-5p, microRNA-335-5p; NCs, negative controls; siRNA, small interfering RNA.

The dysregulation of oxidative stress is crucial for the physiopathology of PE $(35,36)$. Oxidative stress can modulate
miRNA expression in cancer and placental alterations via ROS $(22,23,37)$. A previous study demonstrated that the 
miRNA profile containing miR-335-5p was significantly altered in villous $3 \mathrm{~A}$ cytotrophoblast cells exposed to short-term low concentrations of $\mathrm{H}_{2} \mathrm{O}_{2}$ (38). However, the relationship between ROS and miR-335-5p is not fully understood. The present results suggested that intracellular ROS generation and miR-335-5p expression in JEG-3 cells showed a similar tendency following exposure to only $\mathrm{H}_{2} \mathrm{O}_{2}$ or to NAC pretreatment followed by $\mathrm{H}_{2} \mathrm{O}_{2}$ exposure. Both ROS and miR-335-5p were increased in JEG-3 cells by $\mathrm{H}_{2} \mathrm{O}_{2}$ treatment, whereas the application of NAC reduced this increase. The present results suggested there may be a close link between ROS and miR-335-5p.

The transcription factor p53 is associated with cellular stress and can be regulated by ROS (39). In addition, p53 has pivotal roles in the production of stress-induced miRNAs (22). p53 is involved in the upregulation of miR-200c expression in human umbilical vein endothelial cells after $\mathrm{H}_{2} \mathrm{O}_{2}$ exposure (24). miR-335-5p expression can also be increased in a p53-dependent manner in several human cancer cells (40). Notably, the protein expression, but not mRNA expression of p53 has been reported to be significantly higher in PE placentas compared with normal controls (41). The present study investigated the relationship between ROS, p53 and miR-335-5p. The present results suggested that p53 knockdown reduced miR-335-5p expression in JEG-3 cells and decreased the upregulation of miR-335-5p upon $\mathrm{H}_{2} \mathrm{O}_{2}$ exposure. The present results suggested that $\mathrm{p} 53$ may mediate ROS-induced upregulation of miR-335-5p in JEG-3 cells.

The main limitation of the present study was that the exact location and expression levels of p53, miR-335-5p, Sp1, E-cadherin, N-cadherin and Snail in PE and normal placenta tissues were not investigated. Future studies will need to analyze these factors. Besides the roles in regulating EMT process and migration, a previous study reported that the targets of miR-335-5p participated in the regulation of angiogenesis, as determined using Gene Ontology enrichment analysis (13). Another study demonstrated that the vascular endothelial growth factor (VEGF)-A gene was the predicted target of miR-335-5p by using Mirwalk and Mirtarbase analyses (14). Since VEGF signaling in general, and the levels of VEGF-A and sVEGFR1 in particular, have been implicated in the pathogenesis of PE (4), the potential role of miR-335 in VEGF signaling requires further investigation.

In summary, the present results suggested that miR-335-5p expression levels in trophoblast cells may be increased by ROS in a p53-dependent manner. In addition, miR-335-5p may inhibit cell migration and EMT via the downregulation of Sp1. Since the JEG-3 cell line has been widely used as a cell model for the function of trophoblasts $(42,43)$, the present in vitro experiments may provide novel evidence for the etiology of PE and a potential new therapeutic strategy for patients with PE, particularly for those with dysregulated EMT.

\section{Acknowledgements}

Not applicable.

\section{Funding}

The present study was supported by the Shandong Provincial Natural Science Foundation, China (grant nos. ZR2016HM02 and ZR2019BC059).

\section{Availability of data and materials}

The datasets used and/or analyzed during the current study are available from the corresponding author on reasonable request.

\section{Authors' contributions}

WL carried out experiments and drafted the manuscript. YYM participated in the study design and data analysis. QQS, JL, TTQ and $\mathrm{YH}$ participated in cell culture, operation of the microscope and flow cytometry. QJW conceived the study, and participated in its design, coordination and proofreading. All authors have participated in the work, read and approved the final manuscript.

\section{Ethics approval and consent to participate}

Not applicable.

\section{Patient consent for publication}

Not applicable.

\section{Competing interests}

The authors declare that they have no competing interests.

\section{References}

1. Steegers EA, von Dadelszen P, Duvekot JJ and Pijnenborg R: Pre-eclampsia. Lancet 376: 631-644, 2010.

2. Anderson UD, Olsson MG, Kristensen KH, Akerstrom B and Hansson SR: Review: Biochemical markers to predict preeclampsia. Placenta 33 (Suppl): S42-S47, 2012.

3. Matsuo K, Kooshesh S, Dinc M, Sun CC, Kimura T and Baschat AA: Late postpartum eclampsia: Report of two cases managed by uterine curettage and review of the literature. Am J Perinatol 24: 257-266, 2007.

4. Powe CE, Levine RJ and Karumanchi SA: Preeclampsia, a disease of the maternal endothelium: The role of antiangiogenic factors and implications for later cardiovascular disease. Circulation 123: 2856-2869, 2011.

5. Bartel DP: MicroRNAs: Genomics, biogenesis, mechanism, and function. Cell 116: 281-297, 2004.

6. Mendell JT and Olson EN: MicroRNAs in stress signaling and human disease. Cell 148: 1172-1187, 2012.

7. Mayor-Lynn K, Toloubeydokhti T, Cruz AC and Chegini N: Expression profile of microRNAs and mRNAs in human placentas from pregnancies complicated by preeclampsia and preterm labor. Reprod Sci 18: 46-56, 2011.

8. Choi SY, Yun J, Lee OJ, Han HS, Yeo MK, Lee MA and Suh KS: MicroRNA expression profiles in placenta with severe preeclampsia using a PNA-based microarray. Placenta 34: 799-804, 2013.

9. Hu Y, Li P, Hao S, Liu L, Zhao J and Hou Y: Differential expression of microRNAs in the placentae of Chinese patients with severe pre-eclampsia. Clin Chem Lab Med 47: 923-929, 2009.

10. Chen DB and Wang W: Human placental microRNAs and preeclampsia. Biol Reprod 88: 130, 2013.

11. Hayder H, O'Brien J, Nadeem U and Peng C: MicroRNAs: Crucial regulators of placental development. Reproduction 155: R259-R271, 2018.

12. Jiang F, Li J, Wu G, Miao Z, Lu L, Ren G and Wang X: Upregulation of microRNA335 and microRNA584 contributes to the pathogenesis of severe preeclampsia through downregulation of endothelial nitric oxide synthase. Mol Med Rep 12: 5383-5390, 2015

13. Walz JM, Wecker T, Zhang PP, Cakir B, Gruening B, Agostini H, Reuer T, Ludwig F, Boneva S, Faerber L, et al: Impact of angiogenic activation and inhibition on miRNA profiles of human retinal endothelial cells. Exp Eye Res 181: 98-104, 2019. 
14. Ertekin S, Yildirim O, Dinc E, Ayaz L, Fidanci SB and Tamer L: Evaluation of circulating miRNAs in wet age-related macular degeneration. Mol Vis 20: 1057-1066, 2014.

15. Luo LJ, Wang DD, Wang J, Yang F and Tang JH: Diverse roles of miR-335 in development and progression of cancers. Tumour Biol: Oct 8, 2016 (Epub ahead of print).

16. Livak KJ and Schmittgen TD: Analysis of relative gene expression data using real-time quantitative PCR and the 2(-Delta Delta C(T)) method. Methods 25: 402-408, 2001

17. Ji L, Brkic J, Liu M, Fu G, Peng C and Wang YL: Placental trophoblast cell differentiation: Physiological regulation and pathological relevance to preeclampsia. Mol Aspects Med 34: 981-1023, 2013.

18. Kokkinos MI, Murthi P, Wafai R, Thompson EW and Newgreen DF: Cadherins in the human placenta-epithelial-mesenchymal transition (EMT) and placental development. Placenta 31: 747-755, 2010.

19. Jungert K, Buck A, von Wichert G, König A, Buchholz M, Gress TM and Ellenrieder V: Spl is required for transforming growth factor-beta-induced mesenchymal transition and migration in pancreatic cancer cells. Cancer Res 67: 1563-1570, 2007.

20. Peng M, Hu Y, Song W, Duan S, Xu Q, Ding Y, Geng J and Zhou J: MIER3 suppresses colorectal cancer progression by down-regulating Sp1, inhibiting epithelial-mesenchymal transition. Sci Rep 7: 11000, 2017.

21. Xu Y, Zhao F, Wang Z, Song Y, Luo Y, Zhang X, Jiang L, Sun Z, Miao Z and Xu H: MicroRNA-335 acts as a metastasis suppressor in gastric cancer by targeting Bcl-w and specificity protein 1. Oncogene 31: 1398-1407, 2012.

22. He J and Jiang BH: Interplay between reactive oxygen species and MicroRNAs in Cancer. Curr Pharmacol Rep 2: 82-90, 2016.

23. Bao B, Azmi A, Li Y, Ahmad A, Ali S, Banerjee S, Kong D and Sarkar FH: Targeting CSCs in tumor microenvironment: The potential role of ROS-associated miRNAs in tumor aggressiveness. Curr Stem Cell Res Ther 9: 22-35, 2014.

24. Magenta A, Cencioni C, Fasanaro P, Zaccagnini G, Greco S, Sarra-Ferraris G, Antonini A, Martelli F and Capogrossi MC: miR-200c is upregulated by oxidative stress and induces endothelial cell apoptosis and senescence via ZEB1 inhibition. Cell Death Differ 18: 1628-1639, 2011.

25. Qiao J, Lee S, Paul P, Theiss L, Tiao J, Qiao L, Kong A and Chung DH: miR-335 and miR-363 regulation of neuroblastoma tumorigenesis and metastasis. Surgery 154: 226-233, 2013.

26. Yao L, Li M, Hu J, Wang W and Gao M: MiRNA-335-5p negatively regulates granulosa cell proliferation via SGK3 in PCOS Reproduction, 2018 (Epub ahead of print).

27. Wang J, Wang X, Liu F and Fu Y: microRNA-335 inhibits colorectal cancer HCT116 cells growth and epithelial-mesenchymal transition (EMT) process by targeting Twist1. Pharmazie 72: 475-481, 2017.

28. Zhou XM, Sun R, Luo DH, Sun J, Zhang MY, Wang MH, Yang Y, Wang HY and Mai SJ: Upregulated TRIM29 promotes proliferation and metastasis of nasopharyngeal carcinoma via PTEN/AKT/mTOR signal pathway. Oncotarget 7: 13634-13650, 2016.

29. DaSilva-Arnold S, James JL, Al-Khan A, Zamudio S and Illsley NP: Differentiation of first trimester cytotrophoblast to extravillous trophoblast involves an epithelial-mesenchymal transition. Placenta 36: 1412-1418, 2015.
30. Li XL, Dong X, Xue Y, Li CF, Gou WL and Chen Q: Increased expression levels of E-cadherin, cytokeratin 18 and 19 observed in preeclampsia were not correlated with disease severity. Placenta 35: 625-631, 2014.

31. Du L, Kuang L, He F, Tang W, Sun W and Chen D: Mesenchymal-to-epithelial transition in the placental tissues of patients with preeclampsia. Hypertens Res 40: 67-72, 2017.

32. Fedorova L, Gatto-Weis C, Smaili S, Khurshid N, Shapiro JI, Malhotra D and Horrigan T: Down-regulation of the transcription factor snail in the placentas of patients with preeclampsia and in a rat model of preeclampsia. Reprod Biol Endocrinol 10: $15,2012$.

33. Lee MS, Byun HJ, Lee J, Jeoung DI, Kim YM and Lee H: Tetraspanin CD82 represses Sp1-mediated Snail expression and the resultant E-cadherin expression interrupts nuclear signaling of $\beta$-catenin by increasing its membrane localization. Cell Signal 52: 83-94, 2018.

34. He P, Chen Z, Sun Q, Li Y, Gu H and Ni X: Reduced expression of $11 \beta$-hydroxysteroid dehydrogenase type 2 in preeclamptic placentas is associated with decreased PPARgamma but increased PPARalpha expression. Endocrinology 155: 299-309, 2014.

35. Wu F, Tian FJ, Lin Y and Xu WM: Oxidative Stress: Placenta function and dysfunction. Am J Reprod Immunol 76: 258-271, 2016.

36. Aouache R, Biquard L, Vaiman D and Miralles F: Oxidative stress in preeclampsia and placental diseases. Int J Mol Sci 19: 1496, 2018.

37. Rudov A, Balduini W, Carloni S, Perrone S, Buonocore G and Albertini MC: Involvement of miRNAs in placental alterations mediated by oxidative stress. Oxid Med Cell Longev 2014: 103068, 2014.

38. Cross CE, Tolba MF, Rondelli CM, Xu M and Abdel-Rahman SZ: Oxidative stress alters miRNA and gene expression profiles in villous first trimester trophoblasts. Biomed Res Int 2015: 257090 , 2015.

39. Liu B, Chen Y and St Clair DK: ROS and p53: A versatile partnership. Free Radic Biol Med 44: 1529-1535, 2008.

40. Scarola M, Schoeftner S, Schneider C and Benetti R: miR-335 directly targets $\mathrm{Rb} 1(\mathrm{pRb} / \mathrm{p} 105)$ in a proximal connection to p53-dependent stress response. Cancer Res 70: 6925-6933, 2010.

41. Sharp AN, Heazell AE, Baczyk D, Dunk CE, Lacey HA, Jones CJ, Perkins JE, Kingdom JC, Baker PN and Crocker IP: Preeclampsia is associated with alterations in the p53-pathway in villous trophoblast. PLoS One 9: e87621, 2014.

42. Monteiro LJ, Cubillos S, Sanchez M, Acuña-Gallardo S, Venegas P, Herrera V, Lam EW, Varas-Godoy M and Illanes SE: Reduced FOXM1 expression limits trophoblast migration and angiogenesis and is associated with preeclampsia. Reprod Sci 26: 580-590, 2019.

43. Niu ZR, Han T, Sun XL, Luan LX, Gou WL and Zhu XM: MicroRNA-30a-3p is overexpressed in the placentas of patients with preeclampsia and affects trophoblast invasion and apoptosis by its effects on IGF-1. Am J Obstet Gynecol 218: 249.e1-249. e12, 2018

This work is licensed under a Creative Commons Attribution-NonCommercial-NoDerivatives 4.0 International (CC BY-NC-ND 4.0) License. 